\title{
Design and Application of Photovoltaic Battery Digital Simulator
}

\author{
CAI Wen-hao, LI Yun, LI Du \\ Xi'an University of Science and Technology \\ Xi'an, China \\ e-mail:caiwh5701@163.com,liyun8712@163.com,sxdudu@qq.com
}

\begin{abstract}
This paper uses a simplified mathematical model of engineering panels to accurately simulate the output characteristic of the solar cells only to know individual panels' parameters. On photovoltaic characteristic curve fitting timeliness, the four broken-line method combined with linear interpolation and parabolic interpolation is adopted to accurately simulate the output characteristics of photovoltaic battery. Based on this method, the main circuits to Buck circuit and control section which use the current closed-loop PI control are introduced. The simulation results show that using the four broken line method to piecewise fit photovoltaic battery output characteristics having a high precision. Finally, according to the nonlinear output use the MPPT control the photovoltaic battery simulator and the simulation results show the control precision.
\end{abstract}

Keywords-component;photovoltaic battery,four broken-line method, current closed-loop PI control,MPPT

\section{INTRODUCTION}

Solar photovoltaic power generated with the consumption of conventional energy and the pollution problems produced in use process, making solar power technology take more and more people's attention and study ${ }^{[1][2]}$. Some problems will be caused when using highpower battery array in solar cell research, such as high-power solar cells is expensive, large area, and cost a lot of manpower and material resources in the process of installation. In a short time we can't simulate the output of the solar cell in various environmental conditions, so we also can't to determine the operational status of the system. Then we need a device can accurately simulate the output characteristics of the solar cells in different environments to replace the actual solar cell and greatly reducing the development cycle etc. This device is solar simulator. Essentially, it is a power source and its I-U characteristic of output can simulate the I-U characteristic of solar cell.

Literature 3 shows a structure of a solar cell simulator and combined with the I-U characteristics of the solar cell, proposing a piecewise fitting method based on using a four line method to approximate the photovoltaic cell output; But in the vicinity of the maximum power point is still use the straight-line approximation and a polynomial method which can not accurately simulate the actual curve. From this point, this paper establish an digital simulator to calculate the output of the photovoltaic cells online in order to save storage space; Meanwhile, curve segment fitting of solar cell characteristics by using the polynomial of primary and secondary.

\section{PhOTOVOLTAIC CELL MODEL}

The mathematical model of the solar cell is the basis of achieving digital solar array simulator. Considering unknown parameters in the expression 1 obtained based on the physical characteristics of the photovoltaic cell is not only more but related to temperature and light intensity of the external environment. It is difficult to determine and not easy to apply in practical engineering. In this paper, the literature 4 and 5 proposed engineered model of photovoltaic cells and the model expression is:

$$
\begin{gathered}
I=I_{s c}\left\{1-A\left[e^{(U-D U) / B U_{o c}}-1\right]\right\}+D I \\
\text { Among: } \begin{array}{c}
A=\left(1-I_{m} / I_{s c}\right) e^{-U_{m} / B U_{o c}} \\
B=\left(U_{m} / U_{o c}-1\right) / \ln \left(1-I_{m} / I_{s c}\right) \\
D I=\alpha \cdot(D T) \cdot R / R_{r e f}+\left(R / R_{r e f}-1\right) \cdot I_{s c} \\
D U=-\beta \cdot(D T)+R_{s} \cdot(D I) \\
D T=T-T_{r e f}
\end{array}
\end{gathered}
$$

Where $I_{s c}$ is a short-circuit current of the photovoltaic cell. $U_{o c}$ is open circuit voltage of the photovoltaic cells. $I_{m}$ is the maximum power point current of the photovoltaic cell. $U_{\mathrm{m}}$ is the maximum power point voltage of the photovoltaic cell. $R_{\text {ref }}, T_{\text {ref }}$ respectively are reference value of solar radiation and photovoltaic cell's temperature. $\alpha, \beta$ are current and voltage temperature coefficient under reference sunshine. $\mathrm{R}_{\mathrm{s}}$ is the series resistance of the internal.

Engineering model of Photovoltaic cell is built in Matlab/Simulink according to this expression equation to simulate I-U characteristic of the photovoltaic cell and obtain the output characteristic shown in figure 1.

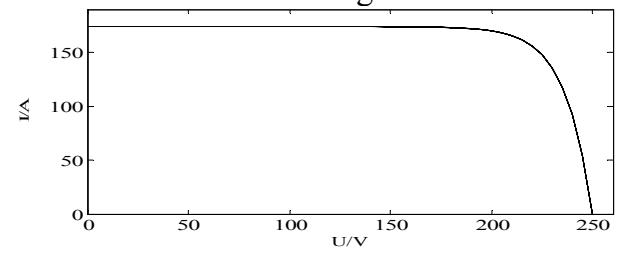

Figure 1. I-U characteristics of PV cell output

\section{I-U CURVE FITTING METHOD}

I-U characteristic of photovoltaic cell can be seen from figure 1.In the low pressure,the output current of the photovoltaic cell is substantially constant and this time the photovoltaic cell like a constant current source .The output 
current of photovoltaic cell decreases rapidly and the degree of nonlinearity of the output characteristic curve significantly increased while the voltage change slightly with the voltage increase. Therefore, during the curve fitting a linear equation is used in the low-pressure section and quadratic polynomial in the high-pressure section.

In the low pressure section the short circuit current point $\mathrm{A}\left(\mathrm{x}_{0}, \mathrm{y}_{\mathrm{o}}\right)$ and another point $\mathrm{B}\left(\mathrm{x}_{1}, \mathrm{y}_{1}\right)$ are endpoints. The primary fitting equation obtained by using linear interpolation calculation relations as:

$$
y(x)=\frac{x-x_{1}}{x_{o}-x_{1}} y_{o}+\frac{x-x_{o}}{x_{1}-x_{o}} y_{1}
$$

When fitting in the high pressure section, the section is divided into three segments as $\mathrm{BC}, \mathrm{CD}$ and $\mathrm{DE}$. Such as fitting $C D$ segment $C\left(\mathrm{x}_{2}, \mathrm{y}_{2}\right)$ and $\mathrm{D}\left(\mathrm{x}_{3}, \mathrm{y}_{3}\right)$ are its endpoints. Using parabolic interpolation relations select $\mathrm{N}\left(\mathrm{x}_{4}, \mathrm{y}_{4}\right)$ as the third point between the two endpoints. The quadratic polynomial equation between $\mathrm{C}, \mathrm{D}$ can be obtained at the same:

$y(x)=\frac{\left(x-x_{3}\right)\left(x-x_{4}\right)}{\left(x_{2}-x_{3}\right)\left(x_{2}-x_{4}\right)} y_{2}+\frac{\left(x-x_{2}\right)\left(x-x_{4}\right)}{\left(x_{3}-x_{2}\right)\left(x_{3}-x_{4}\right)} y_{3}+\frac{\left(x-x_{2}\right)\left(x-x_{3}\right)}{\left(x_{4}-x_{2}\right)\left(x_{4}-x_{3}\right)} y_{4}$

So and so forth,we can get the entire curve fitting equation about photovoltaic cells I-U characteristic. Figure 2 as an example,better fitting effect can get by divide approximated half of the characteristic curve into 4 segments. Intervals were[0,165],[165,205],[205,235] and [235,250].

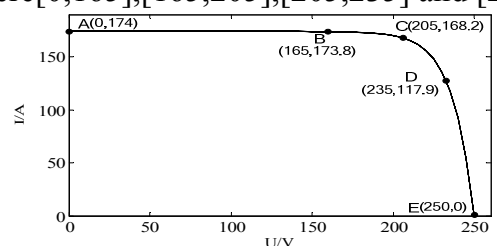

Figure 2. The output current and voltage characteristic curve of PV cell

According to the formula (2) and (3) combined Figure 2 to fit four segments about I-U characteristic curve of the photovoltaic cell obtain the following fitting equation:

From point $\mathrm{A}$ to point $\mathrm{B}$ as 1 fitting section, the fitting equation is:

$$
I=-8.19 \times 10^{-3} U+174 \quad U \in[0,165]
$$

From point $\mathrm{B}$ to point $\mathrm{C}$ as 2 fitting section, fitting equation is:

$$
I=-0.00425 U^{2}+1.4325 U+41.486 U \in[165,205]
$$

From point $\mathrm{C}$ to point $\mathrm{D}$ as 3 fitting section, fitting equation is:

$$
I=-0.0572 U^{2}+23.491 U-2243.615 U \in[205,235]
$$

From point $\mathrm{D}$ to point $\mathrm{E}$ as 4 fitting section, fitting equation is:

$$
I=-0.3076 U^{2}+141.326 U-16106.5 \quad U \in[235,250]
$$

\section{PHOTOVOLTAIC SIMULATOR'S PRINCIPLE}

Photovoltaic Simulator mainly includes two parts about main power and control circuits. The system structure shown in figure 3 . The main power circuit consisted of a single-phase bridge rectifier circuit and a DC chopper circuit. Wherein DC chopper circuit used the Buck circuit, it included the switch $\mathrm{S}$, diode $\mathrm{VD}$, inductance $\mathrm{L}$, capacitance $\mathrm{C}$. When the switch $\mathrm{S}$ is turned on and the diode VD is turned off, the input power provide power to the load through inductor $\mathrm{L}$, while current ${ }^{i_{L}}$ flowing through the inductor increases linearly. Converting electrical energy to magnetic energy stored in the inductance L, capacitance into the state of charge when the inductor current is increased to greater than $I_{0}$ (load current).During the switch $\mathrm{S}$ turn off ,Diode VD is conducting and freewheeling. The current $i_{L}$ through the inductance decreases linearly, before reduced to $I_{0}$, the inductor current provide power to the load and charge to the capacitor. When $i_{L}$ reduced to less than $I_{0}$, the capacitance enter into discharge state provide power to the load in order to maintain the stability of the output voltage. The relationship between the input and output voltage can be determined as follows:

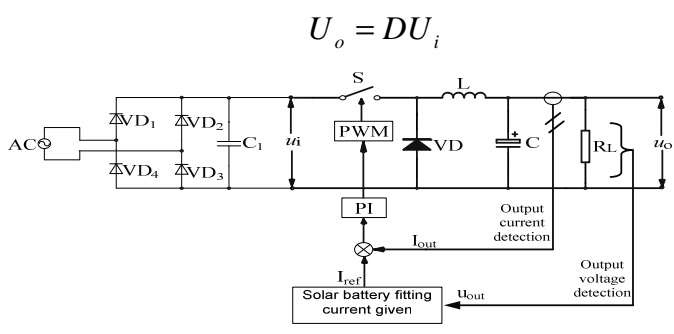

Figure 3. System diagram of photovoltaic battery simulator

Through theoretically analysis the solar simulator and combined with the structure of main circuit can know the simulator actually is an DC switching power supply with special output characteristics. Its function is to complete the conversion from a common DC input to the output characteristics of the photovoltaic array ${ }^{[6]}$.

The control principle according to the system configuration diagram of the simulator, shown in Figure 4.Each link is controlled by a certain connections to complete current and open-circuit voltage control of the system running and put state variables like voltage and current into DSP after isolate. In the control section add an open circuit voltage control to restrict the output voltage does not exceed the open-circuit voltage value in the system .The system will immediately block the PWM signal output to limit the output voltage under the open circuit voltage values, When the output exceeds the open-circuit voltage value. When the system output is normal, the voltage loop does not move.

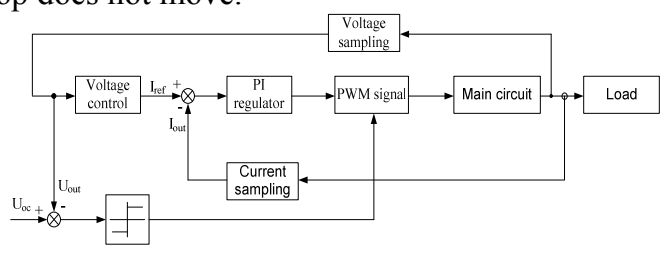

Figure 4. Diagram of current controller 
Specifically, after finishing AD sample of output voltage put the value into DSP. The first to determine the output voltage of this time belongs to which segment of fitting interval. Then calculate the output current of the photovoltaic cell array in accordance with the corresponding fitting equation, and use the value of this current as the output current command value .Put the value that $\mathrm{I}_{\text {ref }}$ subtract actual output current value $\mathrm{I}_{\text {out }}$ into the current PI regulator. Through the regulator adjustment use the output signal to control the pulse width of the PWM. In our implementation, That change the compare register value of DSP to change the pulse width. Ultimately makes the output current $\mathrm{I}_{\text {out }}$ of the system tracks instruction current $\mathrm{I}_{\text {ref }}$ of the real-time changes to simulate the photovoltaic cell ${ }^{[7]}$.

\section{ANALYSIS OF SIMULATOR'S SIMULATION RESULTS}

In order to verify the correctness of the theory, in Simulink build and simulate the module. The simulation used in a solar cell panel main parameter, as shown in the following table. Setting the ambient temperature is $25{ }^{\circ} \mathrm{C}$ light intensity is $1000 \mathrm{~W} / \mathrm{m}^{2}$.

TABLE I. PARAMETERS OF SOLAR BATTERY

\begin{tabular}{cc}
\hline Battery plate parameters & Numerical size \\
\hline Peak voltage & $200 \mathrm{~V}$ \\
Peak current & $170 \mathrm{~A}$ \\
Open circuit voltage & $250 \mathrm{~V}$ \\
Short-circuit current & $174 \mathrm{~A}$
\end{tabular}

System Simulation structure including the power main circuit and control circuit shown in Figure 5 where the load resistor is $1.5 \Omega$

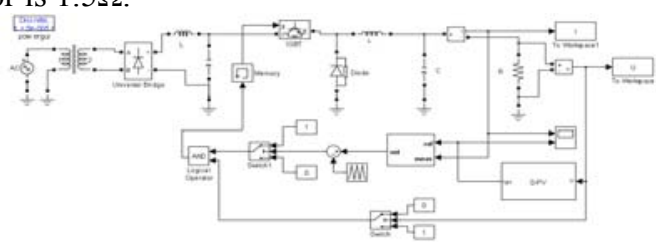

Figure 5. Simulation diagram of photovoltaic battery simulator

The simulation result of the photovoltaic cell simulator shown in figure 6 .The above picture shows the output current of system and the below shows the instruction current. According the polynomial fitting to calculate the current value of the photovoltaic cell 'characteristic curve as instruction value of the system output current . System output current through the PI regulator to track the current command to control the duty cycle of the PWM wave, and thus control the main circuit switching devices to produce a current output to achieve simulation of the photovoltaic cell characteristics. It can be seen that the output current basic track the instruction current about $1.5 \mathrm{~s}$ after a short PI regulation and the current value is approximately $150 \mathrm{~A}$.

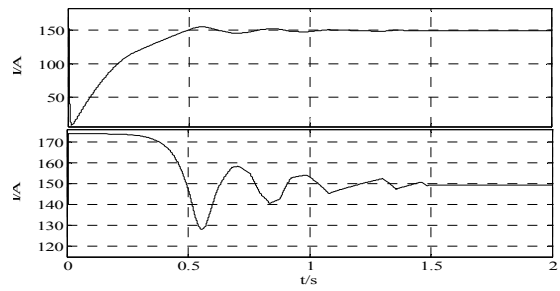

Figure 6. Simulation results of photovoltaic battery simulator

Engineered model of photovoltaic cells building in this paper directly connect to the output resistance in figure 5 to detect output current shown in figure 7 that its size is about $150 \mathrm{~A}$. The value is actually the intersection about two I-U characteristic curve. At the same time, Comparative the output current in figure 6 can be seen that the I-U characteristics of photovoltaic cells are consistent with engineered model of photovoltaic cells.

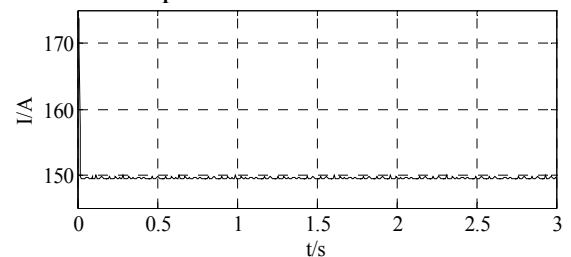

Figure 7. Output current of PV cell direct access load

Changing the size of output resistance sequentially in figure 5 and make the measured voltage and current values of the load sequentially reflected on the I-U characteristic about engineered model of the photovoltaic cell to obtain the result shown in figure 8.As can be seen that the I-U characteristics with photovoltaic cells simulator and engineered model photovoltaic cells reach fitting. The reason that the simulator's output current is slightly higher than the value of the simulation model of the battery is small changes in the part of the voltage in the high pressure section can cause current rapidly change in high-pressure section. Meanwhile, the calculation about interpolation polynomial also has error.

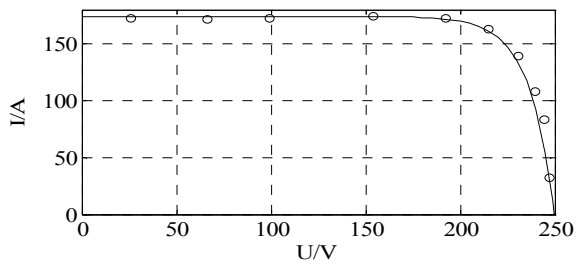

Figure 8. Comparison of characteristic curve and the measured curve about PV cell characteristic

\section{PHOTOVOLTAIC SIMULATOR'S APPLICATION}

Since output characteristics of photovoltaic cell simulator is same as photovoltaic cell, its output will be changed following by the external equivalent load changing which can be seen from the simulation result in the front 
section. In order to make the output of photovoltaic cell simulator in maximum power need to track its maximum power point(MPPT).In this paper use Boost converter as the main circuit which controlled by incremental conductance method of MPPT controller. Incremental conductance method is mainly through compare the instantaneous conductance of the PV array with the variation of conductance to achieve maximum power point tracking. The control flow is described in the literature 8 . The system simulation structure is shown in figure 9 .

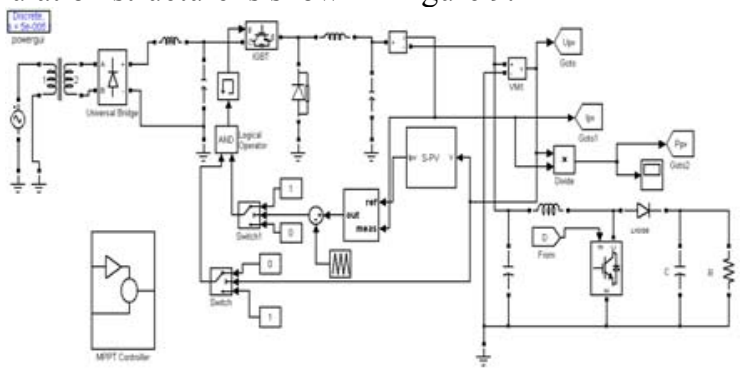

Figure 9. The structure of photovoltaic battery simulator with MPPT function

The control section of the emulator is still use the solar cell's parameters in Table 1. The maximum power output of the simulator is determined by the peak voltage and peak current. The simulation curve of the output power is shown in figure 10 .

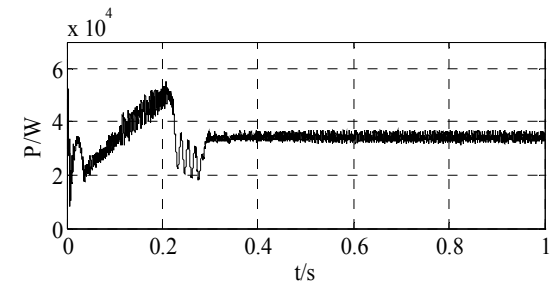

Figure 10. Output power of photovoltaic battery simulator

\section{SUMMARIES}

This paper introduces a mathematical model of an engineering which can accurately simulate the output characteristics only need to know some of the technical parameters provided by the battery manufacturers to analyses the physical model of the photovoltaic cells. The output of the simulator has a higher degree of fitting by using an interpolation and quadratic polynomial interpolation method to fit output characteristic curve of photovoltaic cells. Using this fitting method not only reduces storage space for lookup table ,but also give s full play to the real-time operational capability of digital controller. Finally, the external MPPT controller is used to check simulator's controllability of output characteristic. Once again illustrating that the simulation structure build in this paper can simulate actual output characteristics of photovoltaic cells better and then provide a theoretical basis that use this structure of the power simulator instead of the actual photovoltaic cell.

\section{REFERENCES}

[1] Zhao Zheng-ming,Liu Jian-zheng,Sun Xiao-ying,Yuan Li-qiang.Solar photovoltaic power generation and its application[M].BeiJing:Science Press, 2005.

[2] Wang Ji-dong1,Zhang Xiao-jing,Du Xu-hao,Li Guo-dong. Standards of grid-connection technology for photovoltaic and wind power generations $[\mathrm{J}]$.Electric Power Automation Equipment, 2011,31(11):1-7

[3] Han Pengle. Huang Jianguo Research on and Design of Digital Solarcell Array Simulator [J].Electronic Component And Device Applications.2008, 10 (11):51-54.

[4] Su Jian-hui,Yu Shi-jie, Zhao Wei,Wu Min-da,Shen Yu-liang,He Huiruo.. Investigation on Engineering Analytical model of Silicon Solar Cells[J].ACTA ENERGIAE SOLARIS SINICA, 2001, 22(4): 409412 .

[5] Zhang Jian-po,Zhang Hong-yan,Whang Tao,Ran Hui-juan. Simulation of MPPT Control Algorithms for Photovoltaic System[J].Computer Simulation, 2010, 27(1), 266-270.

[6] Du Ke,Duan Shan-xu,Liu Fei. Research on the Photovoltaic Array Simulator Based on Matlab [J].Telecom Power Technologies, 2006, 23(3): $8-10$

[7] TSE K K, HO M T, CHUNG H S H, etal. A novel maximum power point tracker for $\mathrm{PV}$ panels using switching frequency modulation[C]. IEEE Transactions on Power Electronics, 2002, 17(6) : 980-985.

[8] Cai Wenhao, Ren Hui, Jiao Yanjun, etal. Analysis and Simulation for Grid-Connected Photovoltaic System Based on MATLAB [C]. 2011 International Conference on Electrical and Control Engineering. 2011, 63-66.

[9] OMAN H.Space solar power development[J].IEEEAES Systems Magazine,2000,15(2):3-8

[10] Du Ke.Research on A Digital Photovoltaic Simulator Based on DSP[D].Huazhong University of Science and Technology.2006. 